\title{
Inflation Targeting in New Zealand: Does Policy Match Practice?
}

\author{
Taylor Collins \\ University of the Incarnate Word
}

In this paper, I primarily seek to empirically test whether or not the Reserve Bank of New Zealand (RBNZ) is systematically acting in accordance with their stated monetary policy goal of achieving medium run price stability. In this pursuit, I utilize a series of threshold regressions and vector autoregressions to test responsiveness of the Official Cash Rate to projected inflation deviations from the RBNZ's stated inflation target. Comfortingly, I uncover strong evidence that the RBNZ is in fact systematically setting policy in accordance with their stated policy objective of medium run price stability.

Keywords: inflation targeting, Reserve Bank of New Zealand, Official Cash Rate, threshold regression, VAR, Impulse Response Function

\section{INTRODUCTION}

On December 20th, 1989, New Zealand made monetary policy history by becoming the first country to adopt a formal inflation targeting policy with the passage of the Reserve Bank of New Zealand Act. This Act established that the primary objective of the Reserve Bank of New Zealand is to maintain medium run price stability. Since this passage, many countries have followed suit and adopted official inflation targets of their own. This has led to a wide range of research into the effects of inflation targeting (Honda (2000), Johnson (2002), Odior (2016)) and, more recently, into the effects of a population's trust in central banks (Hayo and Neumeier (2020), Christelis, et al. (2020)). Christelis and his coauthors found strong evidence that an individuals' trust in the European Central Bank has a significant impact on their perception of key macroeconomic variables. However, to my knowledge, no paper as of yet has empirically tested the extent to which central banks are, in fact, trustworthy. We certainly hope they are; but can it be taken for granted?

As noted by Svensson (1997), inflation targeting may be difficult to implement in practice, and evaluation of monetary policy by the public is potentially even more challenging still. So if counteracting pressures make the implementation of an inflation targeting scheme challenging, and if the public would struggle to identify any deviation from such a scheme if one were to occur, can we simply take it on faith that these authorities are systematically acting in accordance with their stated directives? I argue not. It should instead be verified. The purpose of this paper is to begin the process of that verification by testing whether or not the Reserve Bank of New Zealand is systematically acting in accordance with their stated monetary policy goal of achieving medium run price stability.

I start answering this question though the use of a set of simple Threshold Regressions. The purpose of these regressions is to compare the estimated response of the Reserve Bank of New Zealand's primary policy tool, the Official Cash Rate, to projected deviations from the target inflation rate over various periods of time. The RBNZ is known as one of the more transparent monetary authorities in the world, providing 
real time projections of the inflation rate for each quarter up to at least two years into the future. This provides the opportunity to study the time frame at which projected deviations from the inflation target are responded to most strongly. If the RBNZ is in fact systematically working to achieve price stability over the medium term as their mandate dictates, logic would suggest that the OCR should respond more strongly to deviations from the inflation target projected to occur in 2 years over those that are projected to occur next quarter.

Fortunately, the data support that pattern. My series of Threshold Regressions show that the OCR responds most strongly to large deviations projected to occur further in the future. When looking 8 quarters ahead for example, the OCR responds very strongly to all projected deviations from the target inflation rate. But as the forecast horizon shortens, the strength of the OCR response to projected deviations from the inflation target not only diminish in amplitude, but it also changes its response pattern. In the short run, the OCR seems to respond strongly to smaller projected deviations from the inflation target while not responding at all to larger deviations. These conclusions support the position that the RBNZ has been acting systematically to achieve price stability in the medium term above concerns for the present.

From there, I seek to add additional support for this conclusion through a second econometric tool. In this pursuit, I make use of a set Trivariate VARs where I again utilize projected inflation deviations from target over various time periods to determine how the RBNZ responds to various projected inflation deviations. In addition, I begin an elementary exploration into how the market is responding to these inflation projections by incorporating an industrial production index into the estimations.

The set of Trivariate VARs I run utilize an industrial production index, the New Zealand Official Cash Rate, and one of the projected inflation deviation variables from the Threshold Regressions. Supporting the conclusion of the Threshold Regression, the Official Cash Rate responds to projected deviations at longer forecast horizons much more strongly than it responds to deviations at shorter horizons, as expected.

The rest of the paper proceeds as follows. Section 2 discuses New Zealand monetary policy history as it regards their inflation targeting agenda. Section 3 makes use of a set of Threshold Regressions to uncover which forecast horizon is most important in the RBNZ's selection of the Official Cash Rate. Section 4 Makes use of a set of VAR Regressions and Impulse Response Functions to explore how firms are responding to projected future inflation deviations from target. Section 5 Concludes.

\section{MONETARY POLICY AND THE RESERVE BANK OF NEW ZEALAND ACT OF 1989}

I'll begin my brief overview of the history of the New Zealand economy in the 1970s. Since the effects of inflation targeting are the primary points of interest in this paper, I begin in 1970 because I want to communicate an understanding of what lead New Zealand to inflation targeting in the first place. The 1970s are significant because they marked the start of an extended period of time in which New Zealand was exposed to persistently high inflation, fluctuating between 10 and 15 percent. As can be seen in Figure 1, displaying New Zealand's inflation rate between 1960 and 2019, New Zealand experienced a stretch between 1974 and 1987 in which the inflation rate was above $10 \%$ for all but 2 years. And while New Zealand might have never experienced hyperinflation, this period of persistently high inflation coincided with a period of low and volatile economic growth, leaving many New Zealanders with a particularly negative perception of inflation. 


\section{FIGURE 1 \\ INFLATION IN NEW ZEALAND}

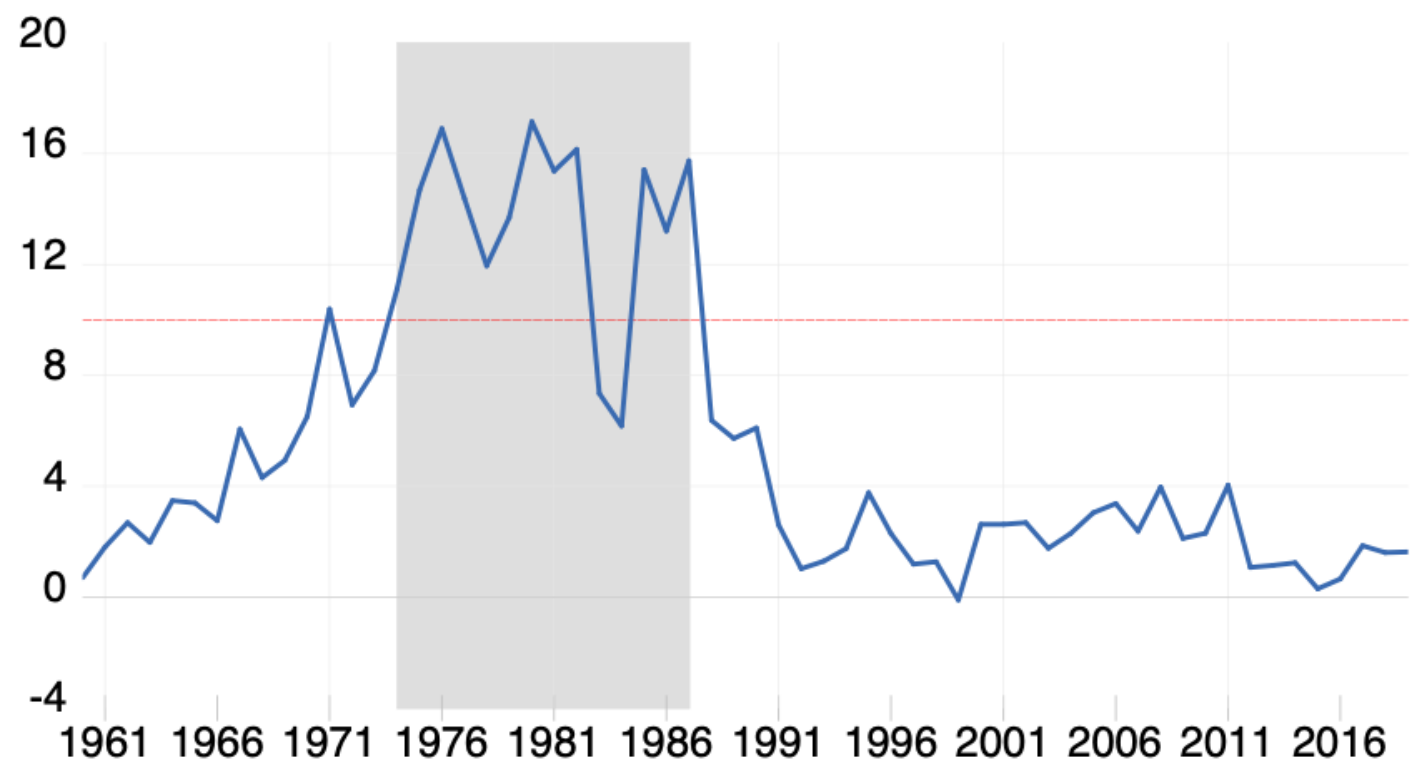

Inflation rate in New Zealand from 1960 through 2019, as measured by the Consumer Price Index. Data obtained from World Bank (2020) through FRED. The 1974 to 1987 era of inflation consistently above 10\%, shaded in gray, drove many of the calls for reform in the late 1980s.

This led to a great deal of support for broad economic reform in the back half of the 1980s. In addition to the Reserve Bank of New Zealand Act of 1989, New Zealand also implemented a floating currency, privatized many state-owned enterprises, implemented public sector reform and welfare reform, and liberalized labor and trade markets. All of these coinciding reforms resulted in a significantly more stable New Zealand economy beginning in 1990 (Bollard et al 1996). Since then, New Zealand has experienced significantly lower inflation and a GDP growth rate that is both higher and more stable than in the period preceding 1989.

But beyond all of these broad reforms to the structure of New Zealand's economy, it is the position of the Reserve Bank of New Zealand that "the best contribution monetary policy can make to the economy is to keep inflation low and stable" (Bollard and Karagedikli (2006)). With the passage of the Reserve Bank of New Zealand Act of 1989, New Zealand began making strides to embrace this policy objective by becoming the first country to adopt an official target range for inflation. This target range is determined jointly by the Government and the Governor according to the Policy Targets Agreement and is currently set at an inflation target band of 1-3 percent on average over the medium term. But when the RBNZ Act of 1989 was first announced, the target band for inflation was set between 0-2 percent. After shifting the target several times in the earlier years, the target band has remained stable since September of 2002 with a 1-3 percent target range, as measured by headline Consumer Price Inflation. The full evolution of the target inflation rate and the target range is provided in Figure 2. As can be seen, the actual inflation rate in New Zealand has only temporarily deviated from this target range since its implementation. The primary policy tool currently used by the Reserve Bank of New Zealand to achieve this price stability is the Official Cash Rate, first going into practice in March 1999.

Further, while the Reserve Bank of New Zealand Act of 1989 assures the RBNZ a certain degree of monetary policy operational independence, an additional defining characteristic of the act is the stringent demand for transparency from the RBNZ. As part of this effort for transparency, the RBNZ must publish 4 Monetary Policy Statements a year and must wait no longer than 6 months between publications. Further, a Select Committee of Parliament reviews each one of the RBNZ's Monetary Policy Statements and implicitly reviews the RBNZ's handling of monetary policy. This means that while the RBNZ has 
operational independence, they also must provide explanations for any policy decisions which deviate from their central objective of inflation stability over the medium term. This is meant to instill strong confidence in the general public that the RBNZ will work systematically to achieve their stated monetary policy goal, an essential component of a successful targeting regime (Bernanke et al 1999).

FIGURE 2

NEW ZEALAND'S TARGET INFLATION RATE

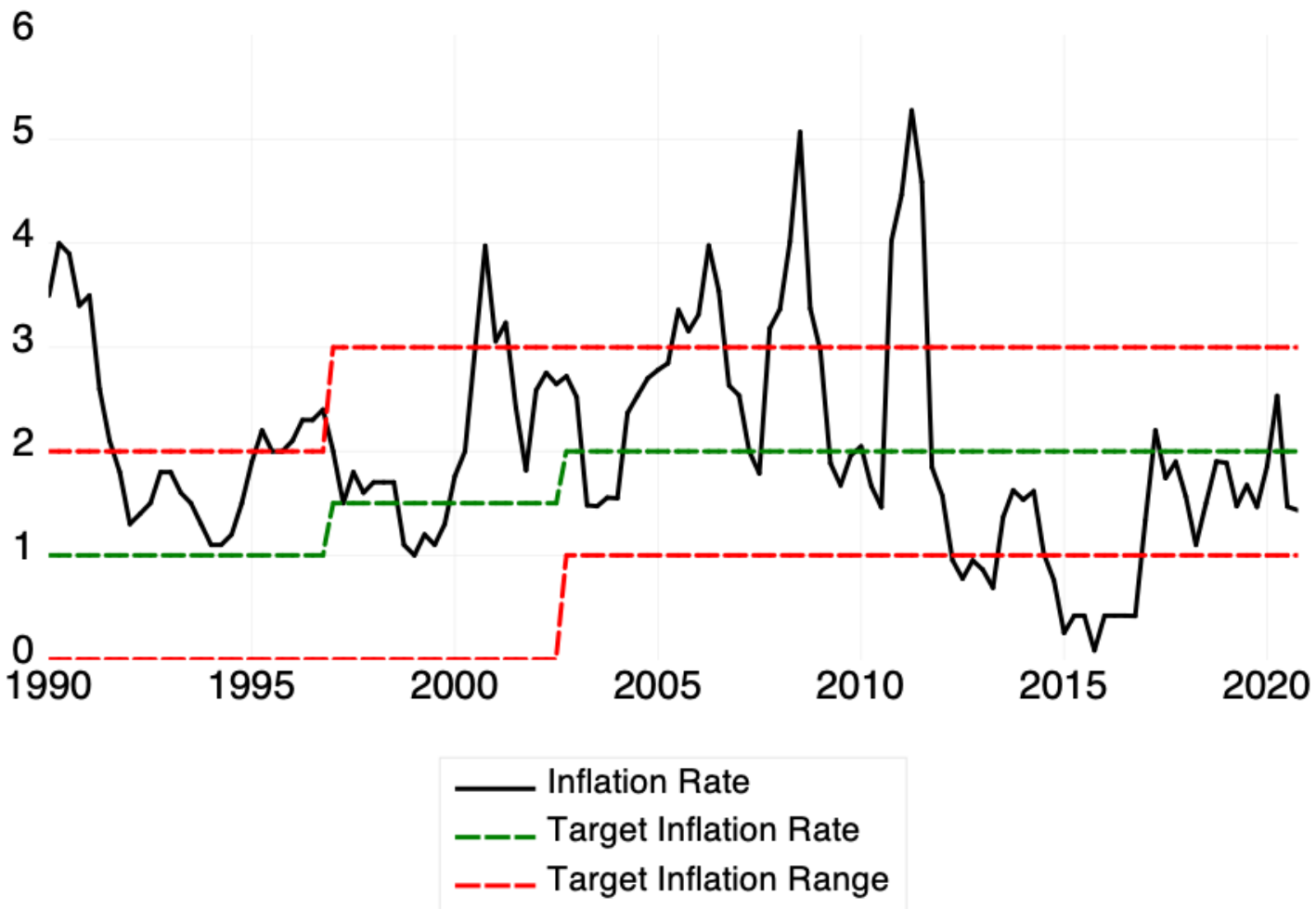

The New Zealand Inflation Rate as measured by the Consumer Price Index compared to the Reserve Bank of New Zealand's stated Inflation Target Range and the center of that range.

With all of these controls in place, there is strong reason to suspect that the Reserve Bank of New Zealand should be acting systematically to achieve their stated objective of medium run price stability. But for the sake of certainty, the rest of this paper will attempt to quantify whether or not that is the case.

\section{THRESHOLD EFFECTS IN PROJECTED INFLATION DEVIATIONS FROM TARGET}

The first objective of this essay is to identify the time frame at which the Reserve Bank of New Zealand responds most strongly to the projected deviation of inflation from its target rate. The RBNZ's stated goal is to be within one percentage point of the $2 \%$ target inflation rate in the medium term. One factor that makes New Zealand unique compared to most inflation targeting countries is the degree of transparency that the RBNZ employs; they provide their official inflation forecasts for at least 2 additional years postdating the release of every Monetary Policy Statement. In this section, I use these inflation forecasts in a set of threshold regressions to test the timeframe at which the RBNZ responds to projected deviations from the target inflation rate most strongly.

I first define $D e v_{i, t}$ to be the projected i-quarter-ahead inflation rate deviation from the target inflation rate, with the projection made in quarter $\mathrm{t}$, defined in levels. The variables are constructed so that $\operatorname{Dev}_{i}$ is positive when the projected inflation rate is above the target rate. In this notation, Dev $_{0}$ is the deviation of 
the realized inflation rate from the target rate. Dev $v_{8}$ is the most forward-looking projection considered. Using these variables, I first run a set of 9 simple threshold regressions in order to determine which time lag leads the RBNZ to respond most strongly. The regression equation is

$I R_{t}=c+\delta_{j} D e v_{i, t}+\epsilon_{t}$

where $I R_{t}$ is the quarterly average of the yield on a 3-month New Zealand Bank Bond and $\delta_{j}$ is the regime $\mathrm{j}$ coefficient where I restrict the maximum number of possible regimes to 6 . Denoting the number of breaks estimated to exist to be $\mathrm{k}$, there then exists a set of increasing threshold values $\lambda_{0}<\ldots<\lambda_{k+1}$ such that we are in regime $\mathrm{j}$ only if $\lambda_{j}<D e v_{i, t}<\lambda_{j+1}$. For any number of estimated breaks $\mathrm{k}, \lambda_{0}$ will always be $\infty$ and $\lambda_{k+1}$ will be $\infty$. Do note that for the exact exploration I wish to conduct, it would be optimal to use the Official Cash Rate as the dependent variable in this regression. However, the Official Cash Rate did not go into use until 1999, while the RBNZ has inflation projections available back to 1997. I use the 3-month yield variable in this regression rather than the OCR since this yield data predates the start of the OCR, and the two series are virtually identical after the OCR's implementation, as seen in Figure 3.

\section{FIGURE 3 \\ NEW ZEALAND'S OFFICIAL CASH RATE}

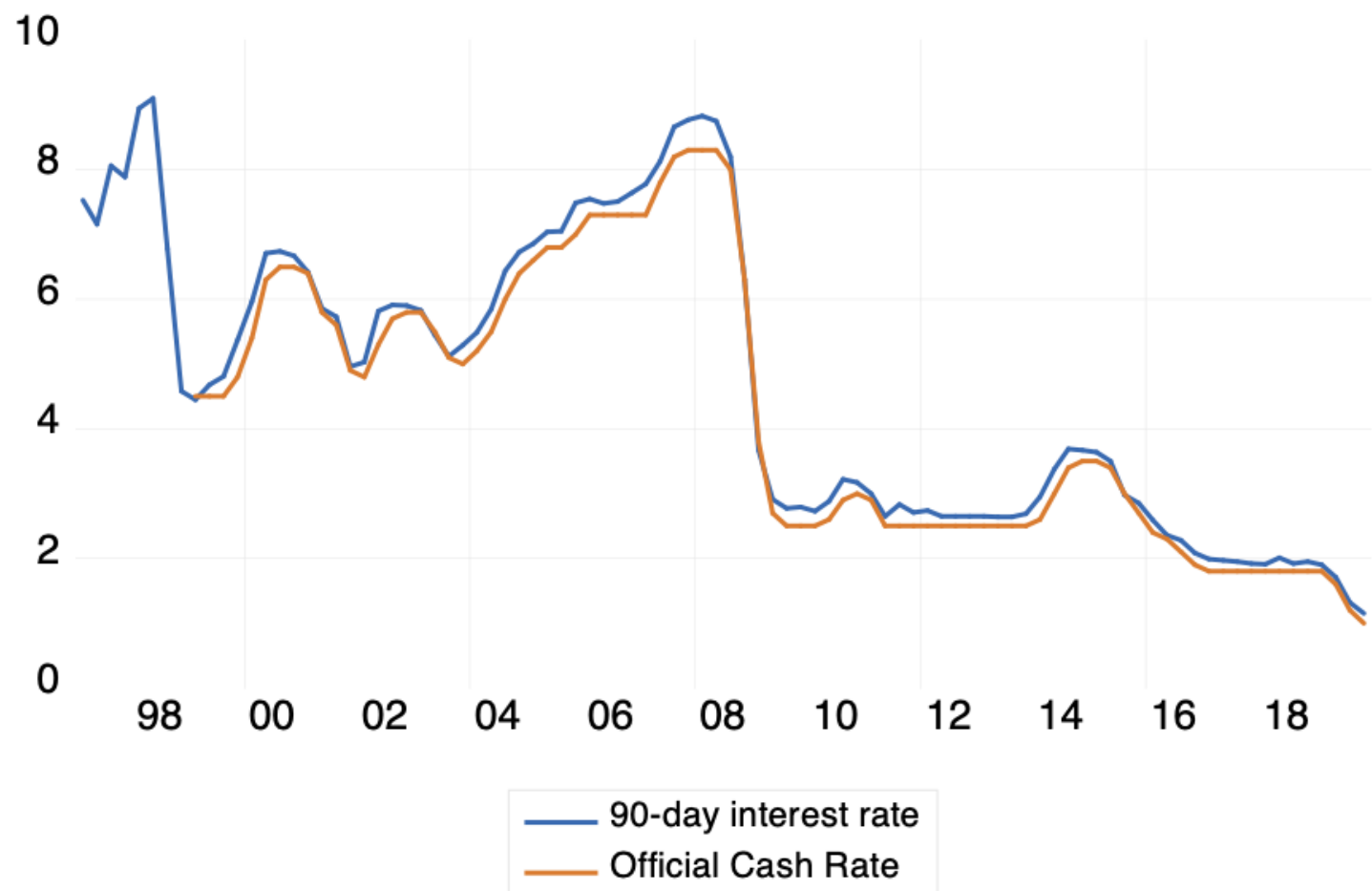

A time series comparison on the Official Cash Rate set by the Reserve Bank of New Zealand, sourced from New Zealand Monetary Policy Statements, and the yield on a 3-month New Zealand bank bond, sourced from OECD (2020a) through FRED.

This regression is estimated using the methodology of Bai and Perron (1998), where the estimated number of breaks is determined using a test of L+1 vs. L sequentially determined thresholds, with $15 \%$ sample trimming. For a given estimated number of breaks k, estimation of the thresholds is achieved by comparing the Sum of Square residuals for all possible sets of $\mathrm{k}$ threshold values. Running this regression separately for each of the $9 D e v_{i}$ variables, I find that no regression estimates the existence of more than two regimes separated by a single threshold break. 
The results of the 9 estimations are provided in Table 1. For the equations finding a single significant threshold break, $\lambda_{1}$ is the estimated level of $D e v_{i}$ at which the break exists. $\delta_{1}$ is the $D e v_{i}$ coefficient when $\operatorname{Dev}_{i}<\lambda_{1}$ and $\delta_{2}$ is the $D e v_{i}$ coefficient when $\operatorname{Dev} v_{i}>\lambda_{1} . \delta$ is the $D e v_{i}$ coefficient across the entire sample when no threshold break is found.

TABLE 1

PROJECTED INFLATION DEVIATIONS FROM TARGET THRESHOLD REGRESSIONS

\begin{tabular}{|c|c|c|c|c|c|}
\hline & c & $\lambda_{1}$ & $\boldsymbol{\delta}_{j}$ & $\delta_{j}$ & $\delta$ \\
\hline $\operatorname{Dev}_{0}$ & 4.699 & 1.40 & $\begin{array}{c}1.769 * * * \\
(0.289)\end{array}$ & $\begin{array}{l}0.515^{*} \\
(0.262) \\
\end{array}$ & -- \\
\hline $\operatorname{Dev}_{1}$ & 4.619 & 1.30 & $\begin{array}{c}1.894 * * * \\
(0.302)\end{array}$ & $\begin{array}{c}0.589 * * \\
(0.262)\end{array}$ & -- \\
\hline $\operatorname{Dev}_{2}$ & 4.666 & 1.12 & $\begin{array}{c}2.058 * * * \\
(0.312)\end{array}$ & $\begin{array}{c}0.590^{* *} * \\
(0.261)\end{array}$ & -- \\
\hline $\operatorname{Dev}_{3}$ & 4.607 & 1.10 & $\begin{array}{c}2.338 * * * \\
(0.360)\end{array}$ & $\begin{array}{c}0.730^{* *} \\
(0.296)\end{array}$ & -- \\
\hline $\operatorname{Dev}_{4}$ & 4.63 & 0.90 & $\begin{array}{c}3.071 * * * \\
(0.456)\end{array}$ & $\begin{array}{c}0.950 * * * \\
(0.344)\end{array}$ & -- \\
\hline $\operatorname{Dev}_{5}$ & 4.397 & -- & -- & -- & $\begin{array}{c}2.185 * * * \\
(4.397)\end{array}$ \\
\hline $\operatorname{Dev}_{6}$ & 4.265 & -- & -- & -- & $\begin{array}{c}2.893 * * * \\
(0.403)\end{array}$ \\
\hline $\operatorname{Dev}_{7}$ & 4.142 & -- & -- & -- & $\begin{array}{c}2.965^{* * * *} \\
(0.463)\end{array}$ \\
\hline $\operatorname{Dev}_{8}$ & 4.025 & - & -- & - & $\begin{array}{c}3.083 * * * \\
(0.557)\end{array}$ \\
\hline
\end{tabular}

These estimated equations indicate that the Reserve Bank of New Zealand is responding more strongly to projected inflation rate deviations from target in the medium term over those of the short term. At the 2year forecast horizon, there is no statistically significant break; it seems that the RBNZ responds to every projected inflation deviation from target equally. Further, it is estimated that the RBNZ will raise the interest rate by about 3.1 percentage points for every additional percentage point that the projected 8-quarter-ahead inflation rate rises above the target inflation rate. As we move from an 8-quarter ahead projection to a 7 quarter-ahead to a 6-quarter ahead to a 5-quarter ahead, a pattern exists wherein the RBNZ is still responding to all projected inflation deviations from target equally, but to successively lesser degrees as the forecast horizon shortens.

Contrasting this to shorter time horizons, a significant threshold break is found when using a projected deviation from target variable at a 4-quarter-ahead or shorter forecast horizon. And for every one of these regressions, the RBNZ is responding to small projected deviations from the target rate much more strongly than they are responding to large deviations. For example, when looking at the $D e v_{3}$ regression, we see that the RBNZ is responding relatively strongly to projected inflation deviations from target of less than 1.1 percentage points (where there is an estimated increase in the interest rate of 2.4 percentage points for every 1 percentage point increase in the projected inflation rate above target) compared to a projected deviation greater than 1.1 percentage points (where there is an estimated increase in the interest rate of 0.73 percentage points for every 1 percentage point increase in the projected inflation rate above target). This pattern continues all the way down to $D e v_{0}$, the realized inflation deviation from target. No forecast horizon illicits a weaker interest rate response than does the realized inflation rate. 
These equations display a very clear pattern: the degree of the interest rate response falls as the forecast horizon is shortened. Each of these regressions indicate that the interest rate responds more significantly to smaller shocks than to large ones at shorter forecast horizons, with the $\delta_{1}$ coefficient larger than the $\delta_{2}$ coefficient for each regression containing a break. At these shorter forecast horizons, the RBNZ does seem to respond to small projected inflation deviations from target, but they respond much less so to large projected deviations from target. And the shorter the time horizon, the less significantly the RBNZ responds.

These results should not be entirely surprising, but they are comforting. It is the stated purpose of the RBNZ to stabilize inflation over the medium term, so a stronger response to inflation deviations forecasted to occur in two years should take precedence over realized inflation deviations from target occurring in the current period. Comparing these threshold regressions to one another thus provides evidence that the RBNZ is in fact working towards this end.

\section{A TRIVARIATE VAR: WHICH INFLATION FORECASTS MATTER?}

I next conduct an unrestricted VAR analysis in order to identify potential effects of the realized and projected inflation rates. Specifically, I want to know the relationship between New Zealand's projected inflation rate deviations from the target rate at various time lags, $D e v_{i, t}$, the yield on a 90 day bank bond, $I R_{t}$, and an Industrial Production Index, $I P_{t}$ (sourced from OECD 2020b). To uncover this, I estimate a set of standard VARs of the form

$B Y_{t}=\lambda_{0}+\Gamma_{1} Y_{t-1}+\Gamma_{2} Y_{t-2}+\Gamma_{3} Y_{t-3}+\varepsilon_{t}$

where

$$
Y_{t-k}=\left[\begin{array}{c}
x_{t-k} \\
I P_{t-k} \\
I R_{t-k}
\end{array}\right]
$$

and the structural identification of shocks is based on the standard Cholesky decomposition as in Sims (1980). In this notation, $x_{t}$ is a placeholder for either inflation, $\mathrm{Infl}_{t}$, or any of the set of previously created deviation variables $D e v_{i, t}$.

I first set $x_{t}=\operatorname{Infl}_{t}$ as a baseline estimation exercise. This paper is most concerned with the impact of the inflation rate on industrial production and the interest rate, so Impulse Response Functions of a onestandard-deviation shock to inflation on the 90-day interest rate and the industrial production index are presented in Figure 4. IRFs are presented with 95\% confidence intervals. As this figure shows, there is a decrease in industrial production, although not close to a statistically significant one, while there is virtually no significant response from the interest rate. This comes at some surprise. In a vacuum, we would expect that higher inflation would lead to raising interest rates, so the fact that there appears to be no impact on the interest rate could be taken as surprising.

However, we see a decidedly different reality when we replace the inflation rate with $D e v_{i}$ in the VAR regression. This is done for each of the $9 D e v_{i}$ variables and the corresponding VAR is estimated. Figure 5 plots the Impulse Response Functions of a 1-standard-deviation shock to each of the $D e v_{i}$ variables on the yield on the 90-day bank bond. Figure 6 presents a comparable grid showing the IRFs of a 1-standarddeviation shock to each of the $D e v_{i}$ variables on the industrial production index. 
FIGURE 4

IMPULSE RESPONSES TO A SHOCK TO INFLATION

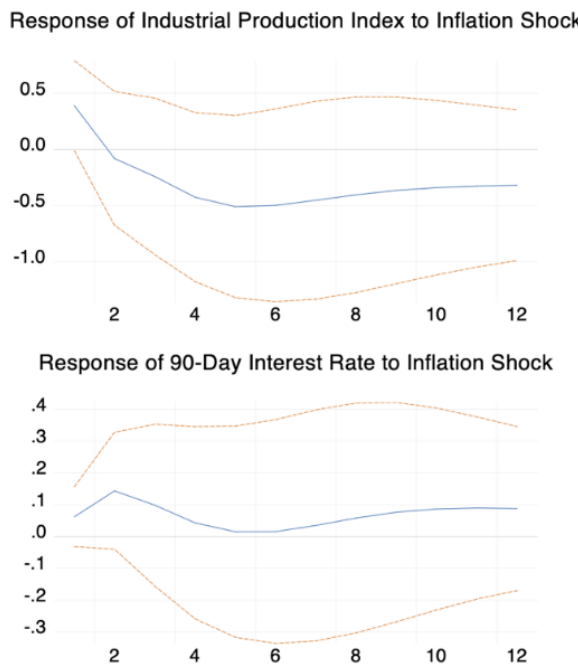

Impulse Response Functions tracking the response of the Industrial Production Index (top panel) and the yield on a 90-day bank bond (bottom panel) to a one standard deviation shock to inflation with $95 \%$ confidence bands

\section{FIGURE 5 \\ IMPACT OF A PROJECTED INFLATION DEVIATION ON INTEREST RATES}
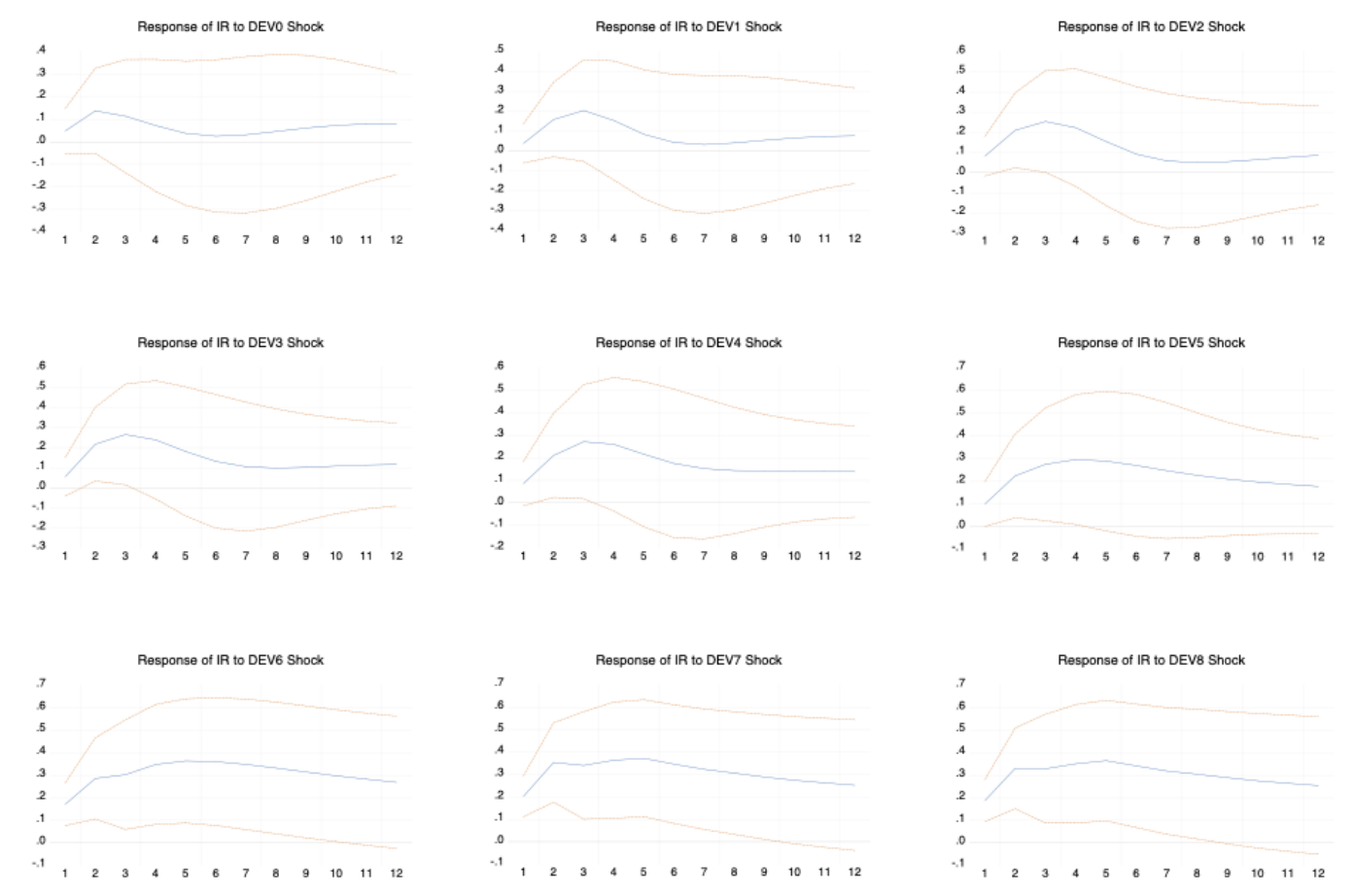

Impulse Response Functions tracking the response of the yield on a 90-day bank bond to a one standard deviation shock to one of the projected inflation deviations from target variables. Each panel maps the IRF (and its 95\% confidence band) obtained from a VAR (3) utilizing the corresponding $\operatorname{Dev}_{\mathrm{i}}$ variable, the industrial production index, and the yield on a 90-day bank bond (labeled IR in the figure). 
Figure 5 tells a clear story. As the inflation forecast horizon rises, the impact of a projected inflation deviation from target rises in amplitude, significance, and persistence. To begin, the interest rate displays nearly no response to a deviation in the realized inflation rate from target. However, the interest rate will respond more strongly to projected inflation target deviations for 1-quarter-ahead, 2-quarter-ahead, and 3quarter-ahead forecasts, but these responses are still small, temporary, and mostly not statistically significant.

Starting at the 4-quarter-ahead forecast, the impact of a 1-standard-deviation shock to the projected deviation of inflation from target appears to become more permanent. However, the amplitude is relatively still small for shocks to the 4-quarter-ahead and 5-quarter ahead projected deviations, neither of which reach a maximum impact beyond 0.3 percentage points, and neither of which are statistically significant for more than a few quarters.

But over the medium term, the impact of a shock to the projected inflation deviation amplifies. The IRF from the $D e v_{6}, D e v_{7}$, and $D e v_{8}$ shocks all reach a peak above 0.3 and display a substantial degree of persistence. For each of them, the $95 \%$ confidence band remains statistically significant up to 2 years in the future. This matches the conclusions of the Threshold Regression analysis in finding that it is projected deviations of inflation from target occurring at a medium run time frame that the RBNZ is responding most strongly to.

When looking to the IRFs in Figure 6, things get a little murkier. When looking at the short run forecasts, the IRFs follow expectations closely. The IRFs found using the $D e v_{0}, D e v_{1}, D e v_{2}, D e v_{3}, D e v_{4}$, and $D e v_{5}$ variables all suggest that a one standard deviation shock to the short-term projected deviations from inflation target will cause a short run decrease in industrial production, although only rarely a statistically significant one. This would be consistent with a story that argues industrial firms scale back production in response to a projected short run inflation shock as input prices rise and the RBNZ raises interest rates, both of which should put downward pressure on the production of firms. Thus, deviations from the inflation target that are expected to occur in the short run behave largely as expected.

\section{FIGURE 6 \\ IMPACT OF A PROJECTED INFLATION DEVIATION ON INDUSTRIAL PRODUCTION}

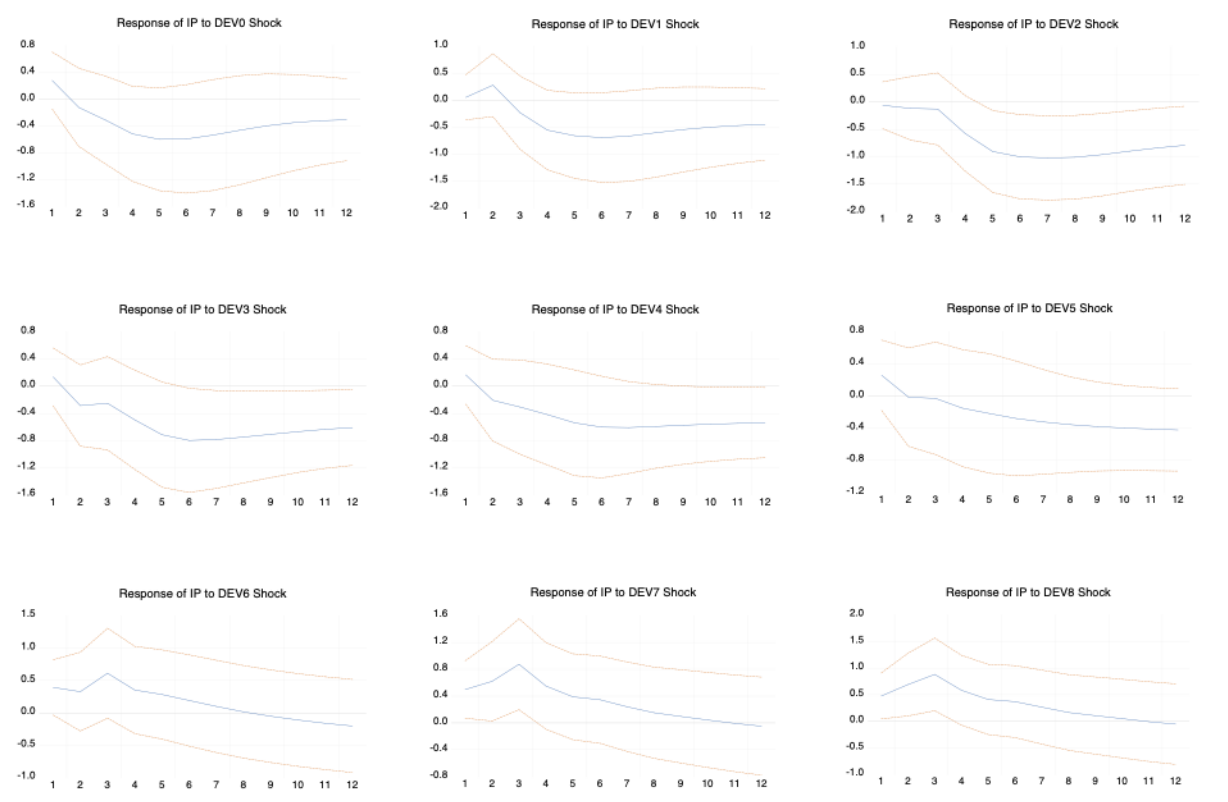

Impulse Response Functions tracking the response of the industrial production index to a one standard deviation shock to one of the projected inflation deviation from target variables. Each panel maps the IRF (and its 95\% confidence band) obtained from a VAR (3) utilizing the corresponding $\operatorname{Dev}_{i}$ variable, the industrial production index (labeled IP in the figure). 
On the other hand, a short-term increase in industrial production is estimated for every projected inflation shock at a 'medium run' time horizon, $D e v_{6}, D e v_{7}$, and $D e v_{8}$. This is partially surprising because the results from the Threshold Regressions indicated that these are the time horizons at which the interest rate responds most sensitively to projected inflation deviations. Consistent with that finding, it would be normal to expect that industrial production rolls back in response to medium-run projected inflation deviations from target as firms respond to the corresponding interest rate response. We however see the direct opposite; industrial production seems to temporarily tick up before converging back to initial levels after about 2 years. This perhaps suggests that at medium time horizons, inflation expectations are driving industrial production decisions to a greater extent than is the official cash rate. These IRFs are consistent with a story that says firms see the projected medium-run inflation rate deviations from target and decide to ramp up production before those price hikes kick in, with the corresponding interest rate increases applying only marginal downward pressure on production.

\section{CONCLUSIONS}

This paper provides some insights to two key questions. First, does the Reserve Bank of New Zealand consistently act in accordance with their stated primary goal of medium-run price stability? And second, how is the New Zealand economy responding to these RBNZ policies?

The first question, and the primary inquiry of this paper, can confidently be answered as a resounding yes. Using sets of both Threshold Regressions and Trivariate VAR regressions, I show that the New Zealand Official Cash Rate responds more strongly to inflation deviations from target projected to occur over the medium term than it responds to projected deviations over shorter time horizons.

The second question is answered less completely, but insights can still be gained. My set of Trivariate VARs provide a starting point. These regressions displayed a pattern wherein industrial production diminishes as a result of inflation being projected to exceed its target rate at short time horizons, but industrial production is estimated to temporarily increase when these target rate deviations are projected to occur over medium-run time horizons (1.5-2 years). This suggests that the interest rate plays a relatively smaller role in driving short and medium run industrial production decisions compared to the inflation rate itself. When inflation is near, it puts immediate downward pressure on the ability of industrial firms to produce. But when it is projected to occur $18+$ months out, firms find it preferable to temporarily increase production today before that projected future inflation becomes realized.

In all, this paper is meant to serve as a jumping off point for studying the effects of inflation targeting policies in New Zealand, the world's first official inflation targeting country. This paper shows that the Reserve Bank of New Zealand is acting systematically to achieve their stated monetary policy goal of medium run price stability. However, this paper also shows that New Zealand firms may not be as concerned with the RBNZ's primary policy tool as they are with the actual inflation rate and the RBNZ's projections for its future.

Moving forward, this paper may serve as a jumping off point for researchers attempting to either confirm or dispute the degree to which central banks are systematically working in accordance with their stated policy agendas. Given that researchers are now quantifying degree to which central bank trust impacts an individual's economic behavior (Christelis et. al (2020), Hayo and Neumeier (2020)), and as a larger number of central banks continue to become official inflation targeters, the question of whether or not inflation targeting central banks deserve our trust is a necessary one to explore. To my great relief, it appears that the Reserve Bank of New Zealand is in fact trustworthy, at least as it pertains to their primary policy agenda. But similar explorations should be conducted on other inflation targeting banks wherever possible. The very simple tests utilized in this paper provide a great jumping off point for that future research.

Journal of Applied Business and Economics Vol. 24(1) 2022131 


\section{REFERENCES}

Bai, J., \& Perron, P. (1998). Estimating and Testing Linear Models with Multiple Structural Changes. Econometrica, 66, 47-78.

Bernanke, B., Laubach, T., Mishkin, F., \& Posen, A. (1999). Inflation Targeting. Lessons from International Experience. Princeton University Press.

Bollard, A., \& Karagedikli, O. (2006). Inflation Targeting: The New Zealand Experience and Some Lesson. Reserve Bank of New Zealand Speeches.

Bollard, A., Lattimore, R., \& Silverstone, B. (1996). A Study of Economic Reform: The Case of New Zealand. Elsevier.

Christelis, D., Georgarakos, D., Jappelli, T., \& van Rooij, M. (2020). Trust in the Central Bank and Inflation Expectations. International Journal of Central Banking, 16(6), 1-37.

FRED. (n.d.). Organization for Economic Co-operation and Development (OECD), 3-Month or 90-day Rates and Yields: Bank Bills for New Zealand [IR3TBB01NZM156N]. Retrieved December 19, 2020a, from https://fred.stlouisfed.org/series/IR3TBB01NZM156N

FRED. (n.d.). Organization for Economic Co-operation and Development, Production of Total Industry in New Zealand [NZLPROINDQISMEI]. Retrieved December 19, 2020b, from https://fred.stlouisfed.org/series/NZLPROINDQISMEI

FRED. (n.d.). World Bank, Inflation, consumer prices for New Zealand [FPCPITOTLZGNZL]. Retrieved December 19, 2020, from https://fred.stlouisfed.org/series/FPCPITOTLZGNZL

Hayo, B., \& Neumeier, F. (2020). Explaining Central Bank Trust in an Inflation-Targeting Country: The Case of the Reserve Bank of New Zealand. Oxford Economic Papers, gpz078. https://doi.org/10.1093/oep/gpz078

Honda, Y. (2000). Some Tests on the Effects of Inflation Targeting in New Zealand, Canada, and the UK. Economic Letters, 66(1), 1-6.

Johnson, D. (2002). The Effect of Inflation Targeting on the Behavior of Expected Inflation: Evidence from and 11 Country Panel. Journal of Monetary Economics, 49(8), 1521-1538.

Odior, E. (2016). Inflation Targeting in an Emerging Market VAR and Impulse Response Function Approach. European Scientific Journal, 8(6).

Sims, C. (1980). Macroeconomics and Reality. Econometrica, 48, 1-48.

Svennson, L. (1997). Inflation Forecast Targeting: Implementing and Monitoring Inflation Targets. European Economic Review, 41(6), 1111-1146. 